مقاله يزوهشى

مجله دانشگاه علوم يزشكى رفسنجان

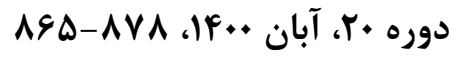

تدوين مدل معادلات ساختارى بيشبينى حس تعلق به مدرسه بر اساس انسجام

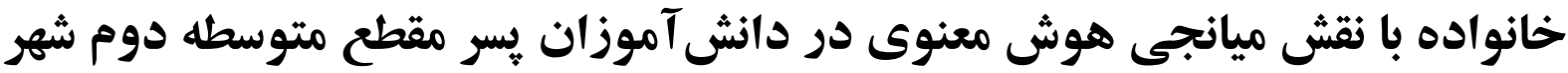

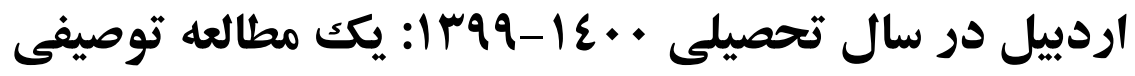

حسين تقوى '، مرتضى جاويديور '، شيرين احمدى

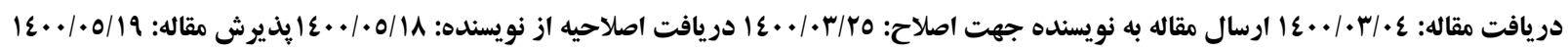

زمينه و هدف: حس تعلق به مدرسه به عنوان يك نياز مهم براى عملكرد خوب دانشآموزان در محيطهاى يادگيرى تأييد

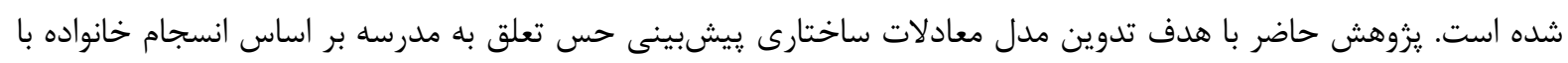

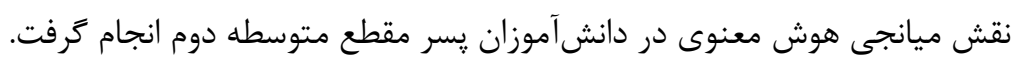

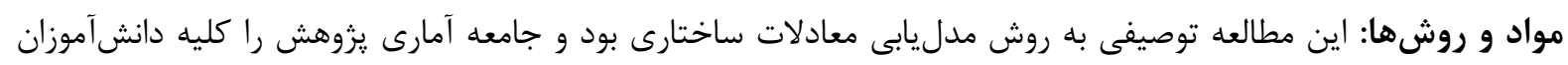

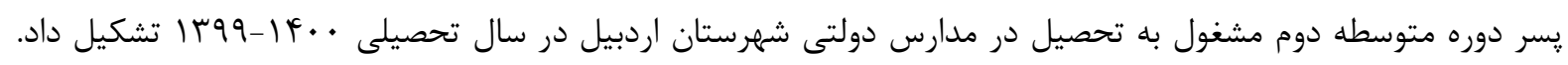

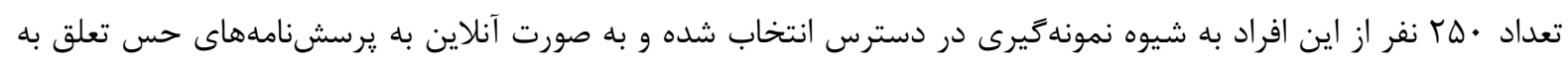

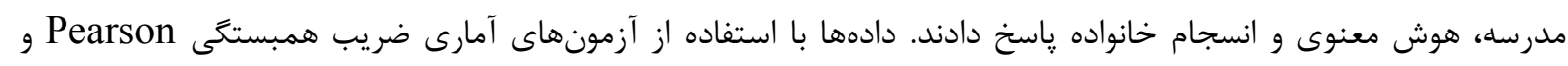
مدليابى معادلات ساختارى تحليل شد. مدرس،

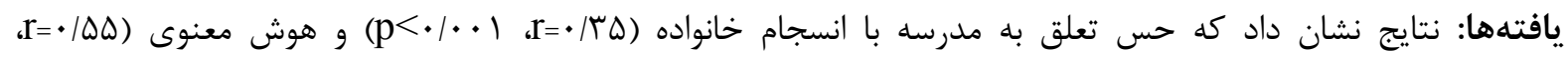

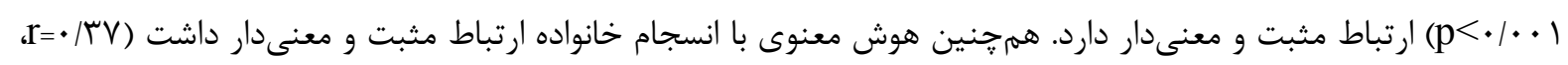

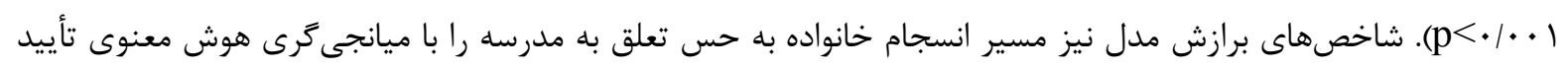

نتيجهَيرى: بلهطور كلى نتايج نشان داد كه انسجام خانواده به صورت مستقيم و غيرمستقيم و با ميانجى گرى هوش معنوى

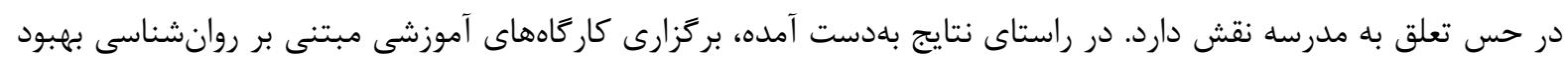

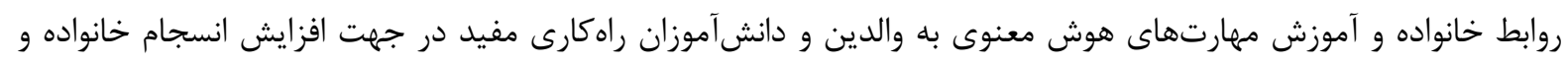
در نتيجه احساس تعلق به مدرسه خواهد بود.

لوازمهاى كليدى: حس تعلق به مدرسه، هوش معنوى، انسجام خانواده، دانش آموزان، اردبيل

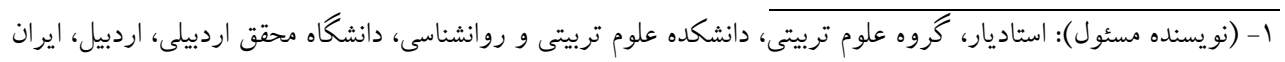

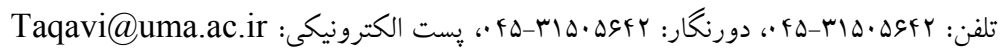

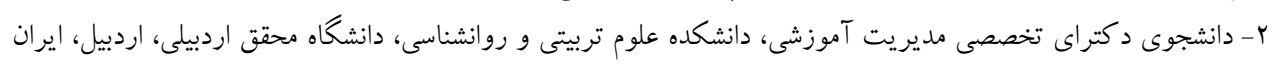

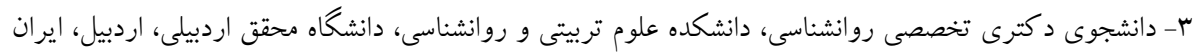


Family ) مدرسه ارتباط داشته باشد انسجام خانواده مقدمه

(cohesion در بين اعضاى خانواده و احساس نزديكى توصيف مىشود

كه با احساس تعلق و يذيرش در خانواده ابراز مىشود [ع]. Ye و همكاران در مطالعات خود نشان دادند كه انسجام خانواده از طريق احساس امنيت دانشآموزان و اختلافات Valido.]V] بين فردى بر سازكارى اجتماعى تأثير مى گذارد و همكاران در مطالعات خود گزارش دادند كه بين ساختار خانواده و انسجام خانواده با حس تعلق به مدرسه ارتباط

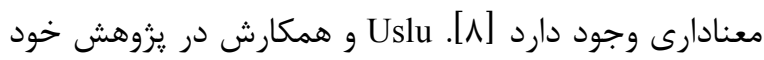
با عنوان حس تعلق به مدرسه و ارتباط با معلمان و درگيرى خانواده گزارش دادند كه بين حس تعلق به مدرسه و ارتباط با معلمان، همسالان و درگيرى خانواده ارتباط معنادارى وجود دارد [9].

يكى از متغيرهايى كه مىتواند ارتباط بين حس تعلق به مدرسه و انسجام خانواده را ميانجى گرى كند هوش معنوى مىباشد. معنويت يكى از (Spiritual Intelligence) نيازهـاى درونسى انسـان اسـت كـهـ برخـى صاحبنظران آن را متضمن بالاترين سطوح زمينههاى رشد شناختى، اخلاقى، عـاطفى، فردى مىدانند [ [ []. هوش معنوى كه سومين نوع هوش است به توانايى افراد براى درك عميق سؤالات وجودى و بينش به سطوح مختلف آكاهى اشاره دارد، مىتواند از طريق عمل ارتقاء يابد و به افراد در تمايز ميان واقعيت و توهم كمك كند [11]]. نتايج مطالعات Upadhyay نشان داد كه افرادى كه خود را دركير كارهاى معنوى مى كردند و به
در آموزش، درى و عملكردهاى فردى به طور فزآيندهاى در حال گسترش است و به طور كلى با افراد از طرق مختلف رفتار مىشود. در اين زمينه، طراحى محيطهاى يادكيرى كه نيازهاى عاطفى دانشآموزان همراه با نيازهاى شناختى آنها مورد توجه قرار مى اعتمادبهنفس، اضطراب، درك، عزتنفس، تمركز كنترل و انخيزه دانشجويى از جمله متغيرهاى عاطفى است كه مىتواند مورد مطالعه قرار گيرد [1]]. حس تعلق به مدرسه به عنوان يك سازه (A sense of belonging to school) عاطفى يكى ديخر از مفاهيم عاطفى مىباشد كه مىتوان آن را به تعلق با احساس يذيرش و احترام در مدرسه، داشتن احساس ورود به مدرسه، احساس افتخار از عضويت در مدرسه و استفاده از مدرسه براى تعريف خود فرد تعريف كرد [Y]. افراد ممكن است وابستخى را به دوستان، خانواده، مدرسه، دانشگاه، باشخاه، سازمان يا حتى از طريق رسانهاى اجتماعى پيدا كنند [ץ]. حس تعلق به مدرسه به عقايد دانشآموزانى اشاره دارد كه به همسالان و بزرگسالان در مدرسه و به يادكيرى خود اهميت مىدهند. ارتباط مدارس به طور گَسترداى به عنوان يك پِيشبينى كننده قابل توجه براى نتايج مثبت دانشآموزان ثبت شده است [ץ]. حس حس تعلق به مدرسه همرجنين مىتواند يك تأثير مثبت بر ״يشرفت تحصيلى و دركيرى در مدرسه داشته باشد [ه]]. در راستاى عوامل مرتبط با حس تعلق به مدرسه در دانشآموزان از جمله عواملى كه مىتواند با حس تعلق به 


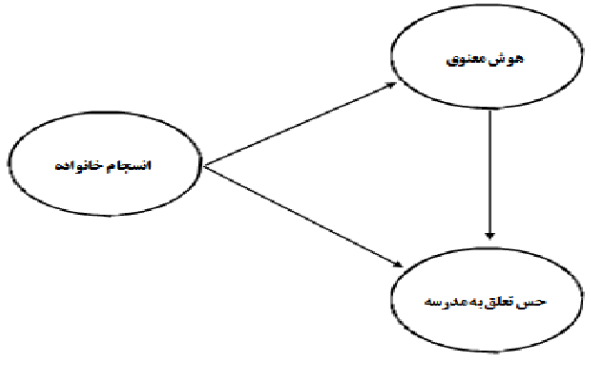

نمودارا - الكوى مفهومى بيشينى حس تعلق به ملدوسه بر اساس

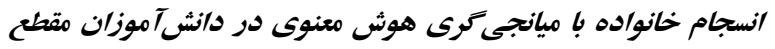

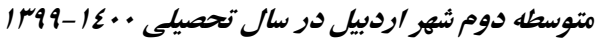

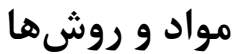

روش مطالعه حاضر از لحاظ هدف كاربردى و از نظر

ماهيت توصيفى به روش مدليابى معادلات ساختارى مىباشد كه با كد اخلاق IR.ARUMS.REC.1400.056 در كميته اخلاق دانشكاه علوم يزشكى اردبيل تصويب شده است. جامعه آمارى يزوهش حاضر را كليه دانشآموزان پِر دوره متوسطه دوم مشغول به تحصيل در مدارس دولتى

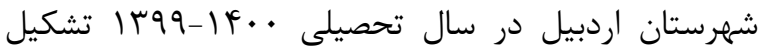
داد. با توجه به اين كه حداقل حجم نمونه لازم در مدلسازى

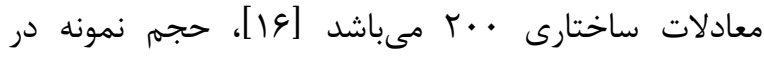
يزوهش حاضر نيز با در نظر كرفتن احتمال أفت نمونهها • • • نفر در نظر ₹رفته شد كه بعد از حذف دادهاى يرت و استانداردسازى دادهها، • بر يرسشنامه وارد تحليل آمارى شد. روش نمونهگيرى مورد استفاده نيز به صورت در

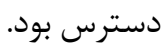

روش جمع آورى اطلاعات به اين صورت بود كه با توجه به وضعيت كرونا و شرايط قرنطينه و عدم دسترسى به دانشآموزان بلهورت حضورى، يرسشنامههاى احساس تعلق به مدرسه، هوش معنوى و انسجام خانواده بهصورت آنلاين از
منابع معنوى اعتماد مى كردند، داراى سطح بالايى از عملكرد تحصيلى بودند [ [ I]. همرجنين Sari و همكاران نشان دادند كه دانشآموزانى كه داراى سطح بالاترى از هوش معنوى بودند عملكرد تحصيلى بهترى هم داشتند [سا]. علاوه بر اين Saranya و همكارش در يزوهش خود به اين نتيجه رسيدند كه بين موفقيت تحصيلى در مدرسه و هوش معنوى در دانشآموزان ارتباط معنادارى وجود دارد و هوش معنوى ״يشبينى كننده پيشرفت تحصيلى دانشآموزان مىباشد

به طور كلى حس تعلق به مدرسه يكى از نيازهاى ضرورى دانشآموزان مىباشد. با اين وجود، كمبود تحقيق در مورد عواملى كه ممكن است بر حس تعلق تأثير بخذارد وجود دارد كه باعث مىشود محققان نتوانند حس تعلق در بين دانشآموزان و جِكونكى افزايش وضعيت روانى مثبت در محيط يادگيرى را به طور كامل پيشبينى كنند. بنابراين، كرجه احساس تعلق به عنوان يكى از نيازهاى انسان در نظر كرفته مىشود، اما هنوز مطالعات بيشترى با عوامل، جمعيتها و فرهنگَهاى مختلف مورد نياز است [ها]. در نتيجه يزوهش حاضر با هدف تدوين مدل معادلات ساختارى ״يشبينى حس تعلق به مدرسه بر اساس انسجام خانواده با نقش ميانجى هوش معنوى در دانشآموزان يسر مقطع متوسطه دوم در قالب مدل مفهومى زير (نمودار () انجام 


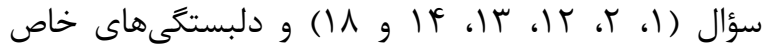

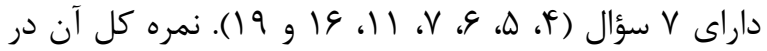
محدوده ...1-1 مىباشد و هر جه فرد نمره بالاترى در اين يرسشنامه اخذ كند داراى حس تعلق بالاترى نسبت به مدرسه است. روش نمرهذذارى آن داراى طيف ينج درجهاى ليكرت از كاملاً مخالفم= 1 تا كاملاً موافقم= ه مىباشد. درباره קايايى اين يرسشنامه، Mouton و همكاران ضريب آلفاى كرونباخ ع/1 • را براى هر ماده كزارش نمودهاند [IV]]. در يزوهشى، ضرايب آلفاى كرونباخ در زير مقياسهاى حس تعلق به مدرسه • ^/| تا ץ/|• به دست آمد و همرجنين نتايج تحليل عاملى اكتشافى و تأييدى مؤيد آن بود كه ساختار يرسشنامه برازش قابل قبولى با دادهها دارد و كليه شاخصهاى نيكويى برازش، مدل را تأييد مىكنند [11]. ضريب پايايى :رسشنامه در مطالعه حاضر به ترتيب Aه|•

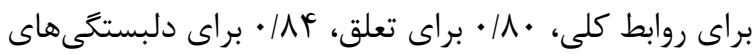
خاص و براى نمره كل احساس تعلق به مدرسه 94/ • به-

$$
\text { دست آمد. }
$$

Spiritual intelligence ) يرسشنامه هوش معنوى questionnaire

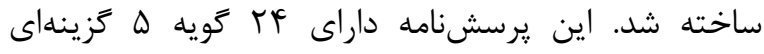
ليكرت نظرى ندارم (نمره •) تا كاملاً درست (نمره \&) و شامل جهار مقياس تفكر وجودى انتقادى، ايجاد معناى شخصى، آكاهى متعالى و گسترش حالت هوشيارى مىباشد.

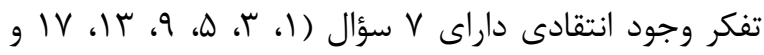
(Y) است كه نمره كل آن ^r-· • مىباشد. زير مقياس ايجاد

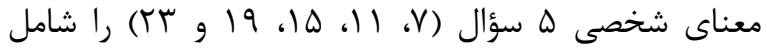

طريق گذاشتن لينك آنها در گروههاى كلاسى و كانالهاى ايجاد شده در شبكهاى مجازى دانشخاه از تاريخ • T اسفند

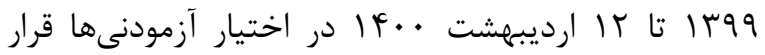

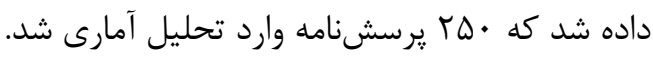
معيارهاى ورود، تمايل به شركت در يزوهش و دانشآموز بودن و معيار خروج، عدم تمايل به شركت در يزوهش بود. جهت رعايت ملاحظات اخلاقى در يزوهش حاضر، ابتداى يرسشنامهها در دو بخش كه بخش اول شامل اطلاعات جمعيت شناختى (سن، وضعيت اشتغال پرر، وضعيت اقتصادى) بود و بخش دوم شامل يرسشنامههاى احساس تعلق به مدرسه، هوش معنوى و انسجام خانواده، در نرمافزار يرسلاين طراحى شده و به همه آزمودنىها اطمينان داده شد كه تمام اطلاعات آنها كاملاً محرمانه حفظ مىشود و در هيج يك از مراحل جمعآورى دادهها، ورود دادهها و تهيه كزارش نهايى، اطلاعات نمونه مورد مطالعه يا اطلاعات آنها فاش نشده و در اختيار هيج شـص حقيقى يا حقوقى قرار

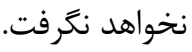

يرسشنامهاى احساس تعلق به مدرسه، هوش معنوى و انسجام خانواده به صورت خلاصه عبارت بودند از: Sense of ) يرسشنامه احساس تعلق به مدرسه belonging to school questionnaire يرسشنامه · T مادهاى است كه توسط Mouton و همكاران طراحى شده است و هدفش مشخص نمودن دانشآموزانى است كه داراى دلبستخى زياد و كم به مدرسه مىباشند. اين يرسشنامه شامل سه مؤلفه است كه عبارتند از: روابط كلى

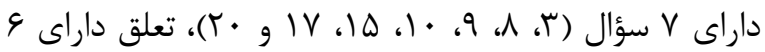


مادر، مدت تعامل، مكان، تصميمزيرى، ارتباط عاطفى، روابط زناشويى و رابطه والدين با فرزندان)، حاكى از كفايت اين مقياس براى ارزيابى همبستخى فرد با والدين بود [بr]. در مطالعه Samani ضريب آلفاى كرونباخ V9/ • و ضريب پايايى

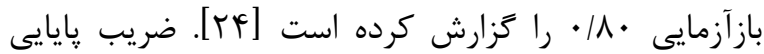
يرسشنامه در مطالعه حاضر 1/19 • بهدست آمد.

دادههاى جمعآورى شده در اين يزوهش با استفاده از ابزارهاى آمار توصيفى جون ميانخين و انحراف معيار و از آزمونهاى همبستخى Pearson با استفاده از نرمافزار SPSS نسخه DT و مدليابى معادلات ساختارى با استفاده از نرمافزار Lisrel نسخه N/A تحليل شد. سطح معنىدارى در آزمونها ه • • • در نظر گرفته شد. نتايج

تعداد • ra دانشآموز يسر مشغول به تحصيل با ميانگَين

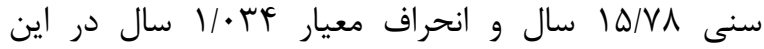
يزوهش شركت داشتند و از لحاظ وضعيت اقتصادى، VV نفر

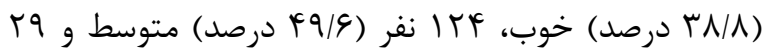
نفر (1/ إ درصد) ضعيف گزارش دادند. از لحاظ وضعيت اشتغال يدر، ها لا نفر (\&\& درصد) داراى شغل آزاد، •V نفر

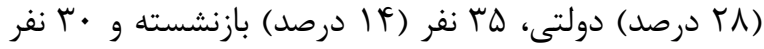

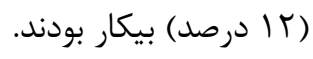

نتايج ضريب همبستگى در جدول ا نشان مىدهد كه حس تعلق به مدرسه با نمره كل انسجام خانواده و هوش معنوى و مؤلفههاى آنها ارتباط مثبت و معنادارى دارد. هم-
مىشود و نمره كل آن ·ץ-· است. زير مقياس آكاهى

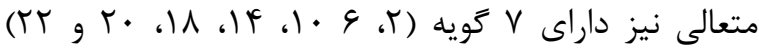
مىباشد و نمره كل اين زير مقياس ^ץ-· است، گسترش

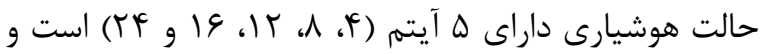
نمره كل زير مقياس آن • ץ-· است. براى به دست آوردن امتياز مربوط به هر بعد، مجموع امتيازات مربوط به تكتك سؤالات آن بعد با هم محاسبه مىشوند. نمره اين مقياس از 99-• متغير است و هر جه فرد نمره بالاترى در اين پرسشنامه اخذ كند داراى هوش معنوى بالاترى است [9 1 ]. ثبات درونى سؤالات مقياس هوش معنوى King به روش آلفاى كرونباخ، AVT/ • و شاخص همبستكى درون خوشهاى •1/99. محاسبه شد. روايى سازه يرسشنامه با استفاده از تحليل عاملى اكتشافى به دست آمد كه ب عامل با ارزش

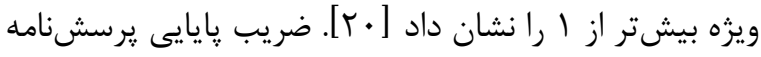
در مطالعه حاضر به ترتيب MA|• براى تفكر وجود انتقادى، /V9/ · براى ايجاد معناى شخصى، • / • براى آكاهى متعالى، و و • براى گسترش حالت هوشيارى و براى نمره كل هوش معنوى 191/ • بهدست آمد.

Family cohesion ) يرسشنامه انسجام خانواده questionnaire [اب[)، توسط Samani Olson تهيه شده است. اين مقياس

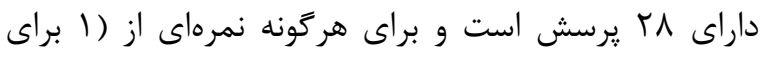
كاملاً موافقم) تا (ه براى كاملاً مخالفم) در نظر كرفته شده If • است [Tr] بيشترين نمره قابل اكتساب در اين آزمون و كمترين RA است. مطالعه Razaviyeh و همكارش در خصوص اين مقياس بر اساس 1 عامل (همبستخى با پبر، 
AV تدوين مدل معادلات ساختارى يِيشبينى حس تعلق به مدرسه بر اساس انسجام خانو اده با نقش ميانجى ...

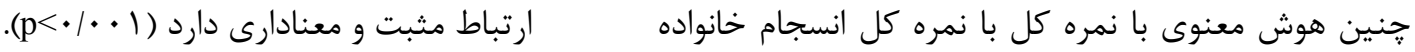

جلدول ا - ميانكين، انحراف معيار و ضرايب همبستكى نمرات آزمودنىها در متغيرهاى حس تعلق به ملدرسه، انسجام خانواده و هوش مون معنوى در

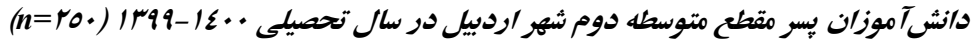

\begin{tabular}{|c|c|c|c|c|c|c|c|c|c|c|}
\hline$(1 \cdot)$ & (9) & $(\Lambda)$ & $(\mathrm{V})$ & $(9)$ & $(\Delta)$ & $(\boldsymbol{F})$ & $(\boldsymbol{\mu})$ & $(r)$ & (1) & متغيرها \\
\hline & & & & & & & & & 1 & انسجام خانواده (() \\
\hline & & & & & & & & 1 & $\cdot / r V * * *$ & هوش معنوى (r) \\
\hline & & & & & & & 1 & $\cdot / 19 * *$ & $\cdot / 10 *$ & تفكر وجودى انتقادى (r) \\
\hline & & & & & & 1 & $\cdot \mid 19^{*} * *$ & $\cdot \mid 9 V * * *$ & $\cdot|r| * * *$ & ايجاد معنادارى شخصى (f) \\
\hline & & & & & 1 & $\cdot / K T * * *$ & $\cdot \mid K r * * *$ & $\cdot / V \Delta * *$ & $\cdot \mid 49 * \%$ & هشيارى متعالى (ه) \\
\hline & & & & 1 & $\cdot / V \wedge$ 米米 & $\cdot / \Upsilon \wedge * * * *$ & $\cdot / 4 \cdot * * *$ & $\cdot / V Y * * *$ & $\cdot \mid \Delta \Gamma_{* * *}$ & كسترش حالت هشيارى (9) \\
\hline & & & 1 & $\cdot / \Gamma Y_{*} * *$ & $\cdot / \pi V * * *$ & $\cdot 10 \cdot * * *$ & $\cdot \mid 49 * *$ & $\cdot / \Delta Y * * *$ & $\cdot / r r_{*} * *$ & روابط كلى (V) \\
\hline & & 1 & $\cdot / 91 * * *$ & $\cdot / \Gamma \Delta * *$ & $\cdot / \pi V * * *$ & $\cdot / 49 * * *$ & $\cdot \mid \uparrow \varepsilon_{* * *}$ & $\cdot \mid \Delta Y * * *$ & $\cdot / T r * * *$ & تعلق (^) \\
\hline & 1 & $\cdot / \vee 9 * * *$ & $\cdot \mid \Lambda r_{*} *$ & •/rG米米 & $\cdot / 4 \cdot * * *$ & $\cdot|\Delta| * * *$ & $\cdot / 4 \Lambda * *$ & $\cdot \mid \Delta F^{F} * *$ & $\cdot / r r_{* * *}$ & دلبستخىىهاى خاص (9) \\
\hline 1 & $\cdot / \vee 9 * * *$ & $\cdot \mid \Lambda r_{*} * *$ & $\cdot / T \zeta * * *$ & $\cdot / \boldsymbol{\uparrow} \cdot * *$ & $\cdot \mid \Delta \Gamma * * *$ & $\cdot / 19 * *$ & $\cdot 10 \cdot * * *$ & $\cdot \mid \Delta 9 * * *$ & $\cdot / \Gamma \Delta * *$ & حس تعلق به مدرسه (•) \\
\hline FF/AF & $19 / 11$ & IT/AV & $\mid \Delta / V \wedge$ & $V / 94$ & $1 \cdot|\Lambda|$ & N/AT & $1 T / K G$ & 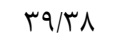 & $9 \vee / 91$ & ميانغين \\
\hline$\pm \mid \vee / \mathcal{F} \wedge$ & $\pm \varphi / r \varphi$ & $\pm \Delta / \Delta q$ & $\pm 9|\varepsilon|$ & $\pm r / 9 V$ & $\pm r / r \varepsilon$ & $\pm r / \Lambda \Lambda$ & $\pm F / \Lambda F$ & $\pm|r| \cdot \Delta$ & $\pm \| / \mathrm{V}$ & انحراف معيار \\
\hline
\end{tabular}

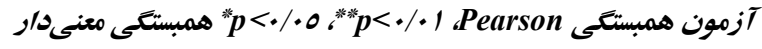

متغيرهاى يیشبين بيشتر است در صورتى كه VIF بزرگتر از • • باشد، مشكل همخطى جدى وجود دارد. مقدار ضريب تحمل (Tolerance) نيز كه براى بررسى همخطى متغيرها به كار مىرود، در محدوده • و ا متغير است. هرجه مقدار آن بزرتتر باشد (نزديك به ()، ميزان همخطى كمتر است و هرجه مقدار آن كوجكتر باشد (نزديك به صفر) همخطى بالا را نشان مى دهد، يعنى اگر ضريب تحمل ^أ • باشد، جاى نخرانى دارد و اخر كوجكتر از | / • باشد، مشكل آفرين است [عr]]. عامل تورم واريانس و ضريب تحمل بهدست آمده براى هر يك از مؤلفهاى متغير ريشبين، همكَى در حد مطلوب بود و بين مؤلفههاى متغير پيشبين همبستخى هاى بزرگ وجود نداشت و همخطى جدى مشاهده نشد.
Durbin- براى بررسى استقلال باقى ماندهها از آماره Watson استفاده شد. اگر بين باقى ماندهها همبستخى متوالى وجود نداشته باشد، مقدار اين آماره بايد به ب نزديك باشد. اخر به صفر نزديك باشد نشان دهنده همبستخى منفى مىباشد. در مجموع اخر اين آماره در محدوده ه/1 تا ه/ץ باشد جاى نخرانى نيست [هץ]. مقدار آماره بهدست آمده براى حس تعلق به مدرسه /AT/ و براى هوش معنوى AD/ بود و اين نتيجه نشان داد كه ييشفرض استقلال باقى ماندهها رعايت شده است. عامل تورم واريانس ( Variance inflation factor; VIF مدل نشان مى دهد. دامنه قابل قبول براى VIF در محدوده ا تا • ا متغير است. هر جه مقدار VIF يك متغير مستقل به يك نزديك باشد، نقش آن متغير در مدل نسبت به ساير 
اسكوئر بهنجار شده و شاخص برازش مقايسهاى در دامنه

$$
\text { مورد قبول قرار دارد [عا]. }
$$

جلدول r - شاخصهاى برازش كلى مدل اصلاحشده در متغيرهاى

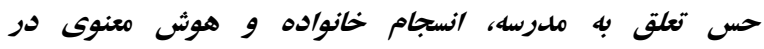

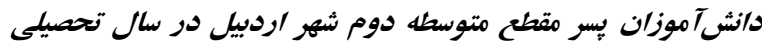
$(n=$ ro.) 1 raq-1z..

\begin{tabular}{|c|c|c|c|c|}
\hline RMSEA & NNFI & CFI & CMIN/DF & شاخص \\
\hline$\cdot / \cdot \Delta \Delta$ &.$/ 90$ & .199 & 1/V9 & مقدار محاسبه \\
\hline$<\cdot / \cdot 1$ & $>\cdot 19$. & $>\cdot 19$. & r-1 & 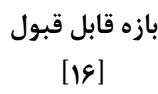 \\
\hline
\end{tabular}

\section{Normed chi-square index; CMIN/DF}

Comparative fit index; $\mathrm{CFI}$

Non-normed fit index; NNFI

Root mean squared error of approximation; RMSEA

نمودار r، بارهاى استاندارد شده مدل يزوهش را نشان مى دهد. در اين مطالعه تمام روابط هوش معنوى و انسجام خانواده با حس تعلق به مدرسه در دانشآموزان معنىدار

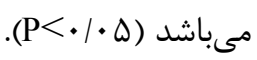

جدول r، شاخصهاى برازش مدل را نشان مى دهد. جهت تعيين كفايت برازش الكوى پيشنهادى با دادهها، شاخصهاى كاى اسكوئر بهنجار شده ) Normed chi-square index; Comparative CCFI (CMIN/DF)، شاخص برازش مقايسهاى ) و ريشه دوم ميانگين مربعات خطاى برآورد (RMSEARoot mean squared error of approximation;) مورد استفاده قرار گرفت. مقادير هر يك از اين شاخصها در محدوده · و ا قرار دارد و مقادير نزديك به و يا بيشتر از • • • نشانه مطلوب بودن مدل مىباشد. شاخص برازش مقايسهاى براى اين مدل \&9/• بوده كه در بازه قابل قبول قرار مى گيرد. از آنجا كه ريشه دوم ميانگين مربعات خطاى برآورد براى مدل هه •/ بهدست آمده است، از طرفى بازه قابل قبول براى آن كمتر از ^^••• مىباشد، يس مىتوان كفت مدل برازش شده مدل مناسبى است. شاخصهاى كاى

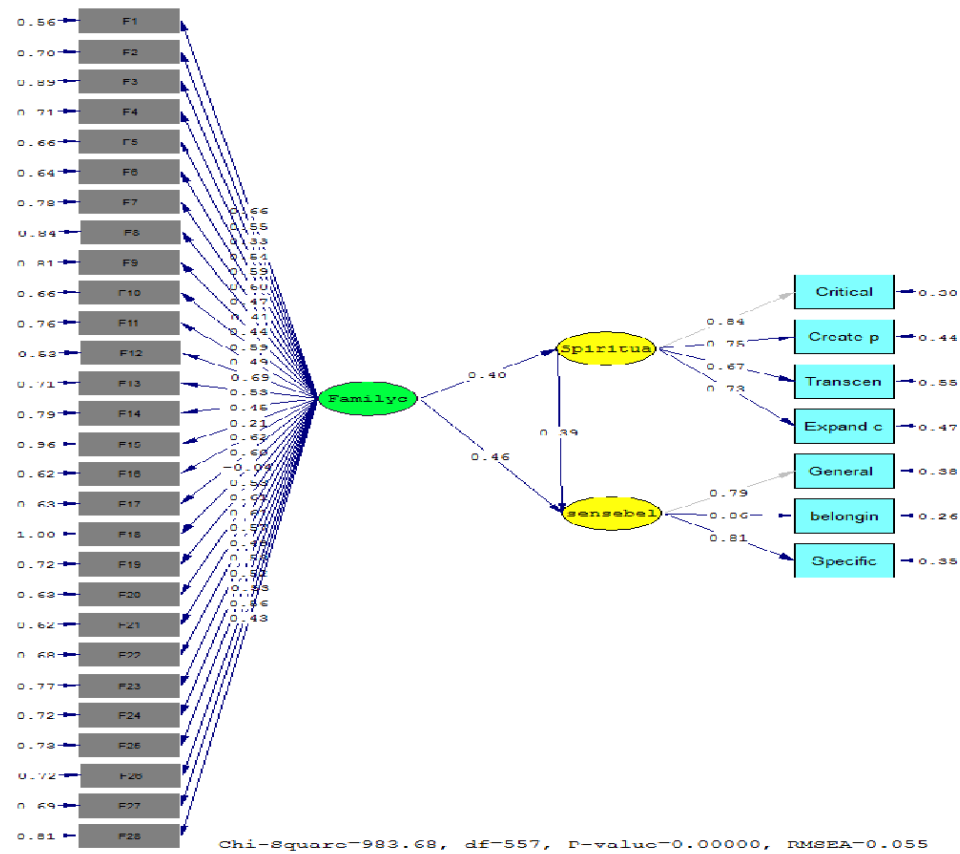

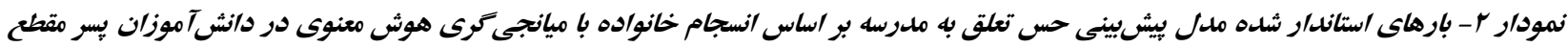

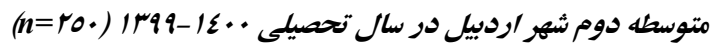




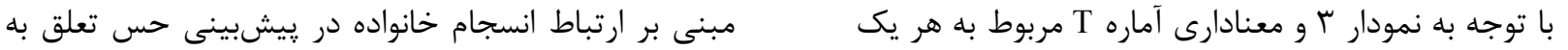

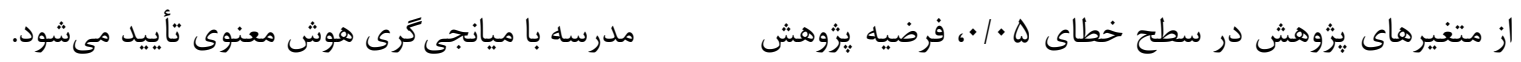

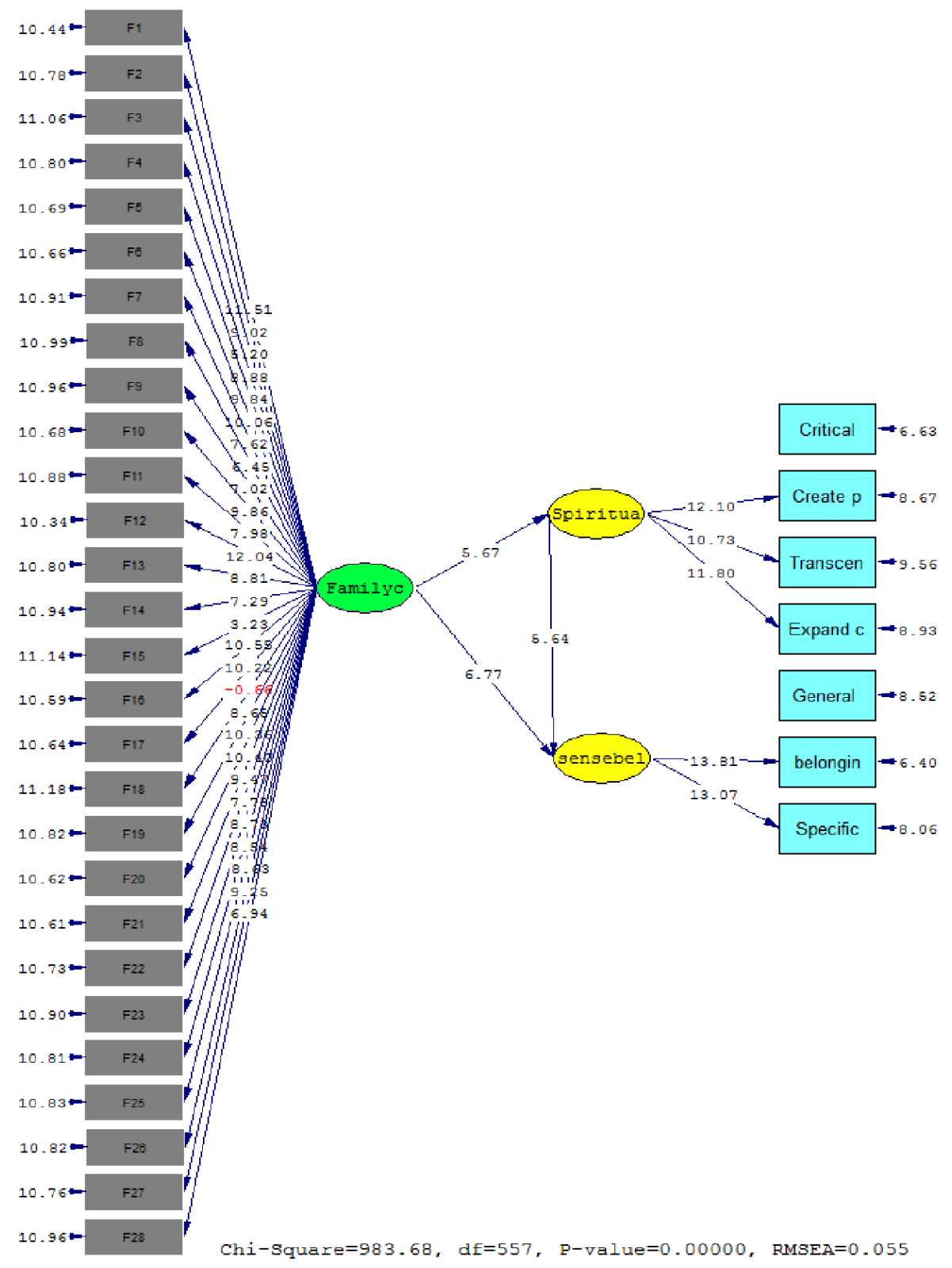

Sense of belonging to the school= Spiritual Intelligence= Family cohesion=

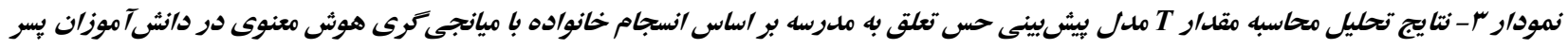

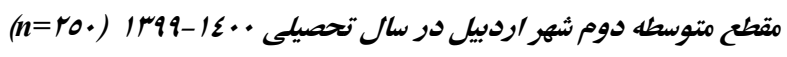




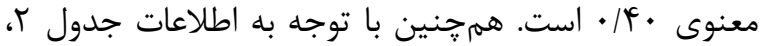
ميزان تأثير غيرمستقيم انسجام خانواده بر حس تعلق به مدرسه با ميانجى گرى هوش معنوى 11/ بوده است.
با توجه به نمودار r و اطلاعات جدول r، تأثير مستقيم انسجام خانواده بر حس تعلق به مدرسه \&\&/•، هوش معنوى بر حس تعلق به مدرسه وَ// • و انسجام خانواده بر هوش

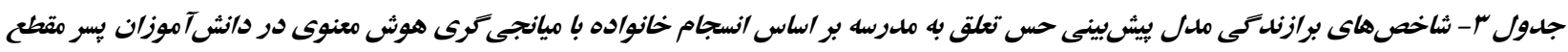

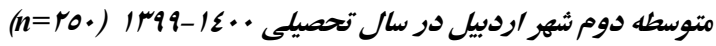

\begin{tabular}{|c|c|c|c|c|c|}
\hline نتيجه & Pقدار P P & مقدار T & ميزان اثر & & تأثيرات مستقيم \\
\hline ت تأييد شده & $\% r$ & GIVV & .148 & حس تعلق به مدرسه & انسجام خانواده \\
\hline تأييد شده &.$\cdot \cdot r$ & $\Delta / \overline{Q V}$ & $\cdot / 4$. & هوش معنوى & انسجام خانواده \\
\hline تأييد شده & . $\cdot r$ & $\Delta / G \psi$ & $\cdot / 49$ & حس تعلق به مدرسه & هوش معنوى \\
\hline نتيجه & مقدار T T T & & ميزان اثر & & تأثيرات غير مستقيم \\
\hline تأييد شده & $r / 99$ & $\cdot / 49 \times \cdot / r q=\cdot / 11$ & حس تعلق به مدرسه & هوش معنوى & انسجام خانواده \\
\hline
\end{tabular}

معضلات اجتماعى روى آورند و آنها رفتارهاى نادرست

فرزندان را محدود و مديريت مى كنند. از طريق اين فرآيند، فرزندان مهارتهاى اجتماعى كسب مىكنند، در بين همسالان مورد استقبال قرار مى مدرسه در آنها قوى مىشوند. برعكس در خانوادههاى با انسجام پايينتر، دانشآموزان تحت نظارت والدين نيستند، بيشتر در معرض يرخاشگرى هستند، خصومت و رفتارهاى يرخطرى كه باعث مىشود محبوبيت كمترى در بين همسالان ييدا كنند [Y^]. علاوه بر اين، دانشآموزان از خانواده منسجم، رفتار اجتماعىتر و بهترى از خود نشان مىدهند. آنها ممكن است بيشتر در فعاليتهاى مدرسه مدار شركت كنند و احساس تعلق بيشترى به مدرسه دارند به طور كلى هنگَامى كه خانواده داراى انسجام باشد و در جريان آموزش فرزندان خود باشند، دانشآموزان انخيزه بيشترى دارند و از نظر عاطفى، اجتماعى و رفتارى سطح بالاترى از خود نشان مىدهند. به عبارتى ديكر، اين
يزوهش حاضر با هدف تدوين مدل معادلات ساختارى ״يشبينى حس تعلق به مدرسه بر اساس انسجام خانواده با نقش ميانجى هوش معنوى در دانشآموزان مقطع متوسطه دوم انجام گرفت. نتايج معادلات ساختارى در يزوهش حاضر نشان داد كه انسجام خانواده با حس تعلق به مدرسه ارتباط مستقيم دارد. اين نتايج با يافتههاى Uslu و همكارش [9]، و و همكاران [Ve بين ساختار خانواده و انسجام خانواده با حس تعلق به مدرسه ارتباط معنادارى وجود دارد، همخوان مىباشد. در تبيين اين فرض مىتوان كفت كه انسجام خانواده و درگيرى مثبت والدين ساز ₹ارى كودكان را در محيط مدرسه ״يشبينى مى كنند [rV]]. در خانواده منسجم، والدين بيشتر دركير آموزش فرزندان مىشوند. آنها فرزندان خود را از نزديك تحت نظر داشته و آنها را راهنمايى مىكنند كه جَّونه به تفكر، تعامل با دوستان و كنار آمدن با ساير 
دانشآموزانى كه از هوش معنوى پايينى برخوردارند دريافت

مى كنند كه اين امر ممكن است تعلق مدرسه آنها را

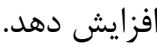

همجنين نتايج معادلات ساختارى نشان داد كه انسجام خانواده بر حس تعلق به مدرسه با ميانجى اثر غيرمستقيم دارد. در اين راستا Sharma و همكاران اظهار داشتند كه هوش معنوى نتيجه بالاترين سطح رشد فردى در زمينههاى شناختى و اخلاقى است و مىتواند بر ساختار خانواده و سلامت روان فرزندان تأثير بخذارد [اس]. در خانواده منسجم، والدين فرزندان را در به دست آوردن مهارتهاى اجتماعى و تحصيلى و ارتقاء هوش معنوى راهنمايى كرده و به آنها براى بهتر انجام دادن تكاليف تحصيلى انخيزه مىدهند كه اين امر منجر به افزايش كارآيى اجتماعى و تحصيلى دانشآموز مىشود. بنابراين دانشآموزان به خود ايمان بيشترى خواهند داشت و اهداف خود را توسعه مىدهند كه به مشاركت آنها در تكاليف تحصيلى و فعاليتهاى مدرسه محور كمك مى كند. استفاده از الكوى ساختارى امكان آزمودن فرضيات ييجيده را فراهم مى كند. با اين وجود، مقطعى بودن يزوهش حاضر مانع از نتيجهگيرى على و شناسايى دقيق ماهيت اين روابط مى گردد و محدود بودن يزوهش به دانشآموزان اردبيل دو محدوديت عمده مطالعه حاضر بود كه در مطالعات آتى با هدف نتيجهگيرى ارتباط على و روشن كردن فرآيند زمانى بين سازههاى يزوهش و بررسى فرآيند تغييرات آنها در روند زمانى، انجام تحقيقات طولى و اجراى يزوهش در ديخر مناطق جغر افيايى بيشنهاد مى
دانشآموزان به دليل بازخورد مثبتى كه در خانواده دريافت مى كنند، بيشتر علاقه به مدرسه دارند. نتايج معادلات ساختارى نشان داد كه هوش معنوى با حس تعلق به مدرسه ارتباط دارد. اين نتايج با يافتههاى و همكارش [Y Saranya همكاران [ז1]] مبنى بر اينكه بين موفقيت تحصيلى در مدرسه و هوش معنوى در دانشآموزان ارتباط معنادارى وجود دارد و هوش معنوى يِيشبينى كننده ييشرفت تحصيلى دانشآموزان مىباشد، همخوان مىباشد. در تبيين اين فرض مىتوان كفت برخى از محققان ادعا مى كنند كه هوش معنوى نوعى هوش است كه شامل مجموعهاى از ظرفيتها و توانايىها است و افراد را قادر مىسازد مشكلات را حل كنند و به اهداف روزمره خود برسند [?]]. اين تعريف فرض مى كند كه معنويت ممكن است در اصطلاحات انطباقى، شناختى-انخيزشى مفهومسازى شود. به دنبال اين خط فكرى، هوش معنوى از مجموعهاى از توانايى تشكيل شده است كه ممكن است بخشى از دانش تخصصى يك شخص باشد و در شرايط حل مسئله مرتبط باشد. به عبارت ديخر، به واسطه هوش معنوى افراد سطح آكاهى و خردمندى مناسبى را كسب مىكنند كه ممكن است جستجوى معناى فرد را در زندگى تسهيل كند و ممكن است به او در دستيابى به اهداف يِيجيده معنوى كمك كند [ـr]. بر اين اساس دانشآموزانى كه هوش معنوى بالاى دارند، هنكام مواجهه با مشكلات و خالشهاى تحصيلى بهتر پيش مىروند و به تكاليف خود يایبند مىمانند و بيشتر به مدرسه علاقه دارند، عملكرد تحصيلى بهترى دارند و از معلمان بازخورد مثبت بيشترى نسبت به 


\section{تشكر و قدردانى}

اين يزوهش با حمايت مالى معاونت بزوهشى دانشكاه محقق

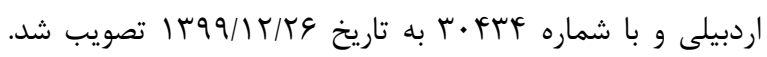

بدينوسيله از كليه همكارىهاى مشفقانه مدير، مشاور و معلمان مدارس جهت همكارى در اجراى يزوهش در شهرستان اردبيل و كليه دانشآموزان شركت كننده در يزوهش و همرجنين از دانشعاه محقق اردبيلى بابت حمايت مالى از اين يزوهش نهايت قدردانى

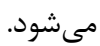

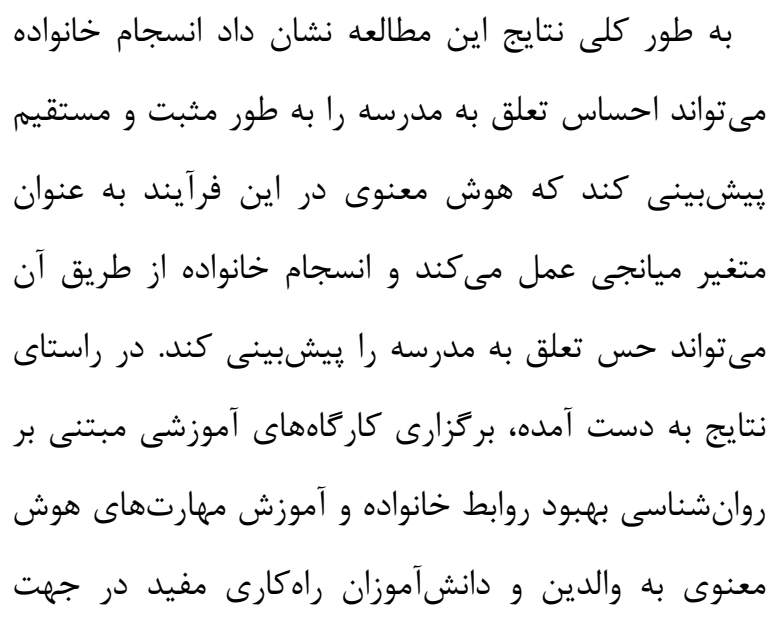

\section{References}

[1] Yildiz VA, Kiliç D. Investigation of School Burnout and School Attachment among Secondary School Students. J Educ Sci Theory Pract 2020; 20(3): 4455.

[2] Fan X, Luchok K, Dozier J. College students' satisfaction and sense of belonging: differences between underrepresented groups and the majority groups. J Soc Sci 2021; 1(1): 1-22.

[3] Sukor MSM, Panatik SA, Noordin NF. The Influence of Humor Styles on The Sense of Belonging among University Students. J Sains Human 2020; 12(1): 4650.
[4] Liu Y, Kim H, Carney JV, Chung KS, Hazler RJ. Individual and contextual factors associated with school connectedness in the context of counseling in schools. J Couns Dev 2020; 98(4): 391-401.

[5] Allen K, Kern ML, Vella-Brodrick D, Hattie J, Waters L. What schools need to know about fostering school belonging: A meta-analysis. J Educ Psychol Rev 2018; 30(1): 1-34.

[6] Niehues W, Kisbu-Sakarya Y, Selcuk B. Family cohesion facilitates learning-related behaviors and math competency at the transition to elementary school. J Early Educ Dev 2021; 32(2): 134-47. 
[7] Ye B, Lei X, Yang J, Byrne PJ, Jiang X, Liu M, et al. Family cohesion and social adjustment of chinese university students: the mediating effects of sense of security and personal relationships. J Curr Psychol $2019 ; 40(1): 1-12$.

[8] Valido A, Ingram K, Espelage DL, Torgal C, Merrin GJ, Davis JP. Intra-familial violence and peer aggression among early adolescents: Moderating role of school sense of belonging. J Fam Violence 2021; 36(1): 87-98.

[9] Uslu F, Gizir S. School belonging of adolescents: The role of teacher-student relationships, peer relationships and family involvement. Educational Sciences: Theory and Practice 2017; 17(1): 21-40.

[10] Farrow J. Spirituality and self-awareness. J Friends Quarterly 1984; 19(2): 213-323.

[11] Vaughan F. What is spiritual intelligence? J Humanist Psychol 2002; 42(2): 16-33.

[12] Upadhyay S. Can spiritual intelligence influence research performance in higher education? Framework for human resource development in higher education. $J$ RAMP 2017; 1(28): 153-73.

[13] Sari RK, Zulaikhah ST, Mahdiyah D. Study on emotional intelligence and spiritual intelligence as a prediction of students cumulative'grade points average. J Crit Rev 2019; 6(5): 1-6.

[14] Saranya R, Sangeetha T. A study of spiritual intelligence in relation to achievement in science among secondary school students in Coimbatore educational district. J Res Granthaalayah 2017; 30(5): 17-21.

[15] Museus S, Chang T. The Impact of Campus Environments on Sense of Belonging for FirstGeneration College Students. J Coll Stud Dev 2021; 62(3): $367-72$.

[16] Homan A. Structural Equation Modeling Using LaserL Software. Tehran: Samt; 2014; p 22. [Farsi]

[17] Mouton SG, Hawkins J, McPherson RH, Copley J. School attachment: Perspectives of low-attached high school students. J Educational Psychology 1996; 16(3): 297-304.

[18] Pezhohandeh A, farzad V, kadivar P. Investigating psychometric characteristics of school attachment questionnaire. J Educ Res 2012; 8(33): 1-26. [Farsi]

[19] King U. Can spirituality transform our world. J Study of Spirituality 2011; 23(1): 17-34.

[20] Sharif Nia H, Haghdoost A, Ebadi A, Soleimani M, Yaghoobzadeh A, Abbaszadeh A, et al. Psychometric 
properties of the king spiritual intelligence questionnaire (KSIQ) in physical veterans of Iran-Iraq warfare. J Mil Med 2015; 17(3): 145-53. [Farsi]

[21] Olson D. Circumplex Model of Marital and Family Systems, Empirical Approaches to Family Assessment special edition of the. J Fam Ther 1999; 22(2): 144-67.

[22] Samani S. Causal model for family solidarity and emotional independence and adjustment. Shiraz: Shiraz University; 2002. [Farsi]

[23] Razaviyeh A, Samani S. Investigating the Factory Structure of the Stanberg and Silver Leaf Emotional Independence Scale for Use in Iran. Paper presented at the Sixth Congress of Psychiatric and Psychological Research in Iran; Tehran: Shahid Beheshti University of Medical Sciences; 2000. [Farsi]

[24] Samani S. Developing a family cohesion scale for Iranian adolescents. Iran J Psychiatry Clin Psychol 2004; 14(2): 162-8. [Farsi]

[25] Habibi A. SPSS software application training. Ed F, editor: Electronic Publishing 2018; p: 15. [Farsi]
[26] Karimi R. Easy guide of statistical analysis with SPSS. Ed F, editor. Tehran 2015; p 25. [Farsi]

[27] Coe J, Davies P, Sturge-Apple M. Family cohesion and enmeshment moderate associations between maternal relationship instability and children's externalizing problems. J Fam Psychol 2018; 32(3): 289-98.

[28] Xie W, Chen W, Zhang L. The effect of square dance on family cohesion and subjective well-being of middle-aged and empty-nest women in China. $J$ Health Care for Women International 2020; 42(1): 43-57.

[29] Lim J, Shon E. The dyadic effects of family cohesion and communication on health-related quality of life: The moderating role of sex. $J$ Cancer nursing 2018; 41(2): 156-65.

[30] Skrzypińska K. Does spiritual intelligence (SI) exist? A theoretical investigation of a tool useful for finding the meaning of life. J Relig Spiritual Aging 2021; 60(1): $500-16$.

[31] Sharma S. A study of relationship between spiritual intelligence and adjustment in relation to their age and family system of working women. Indian J Posit Psychol 2017; 8(3): 326-42. 


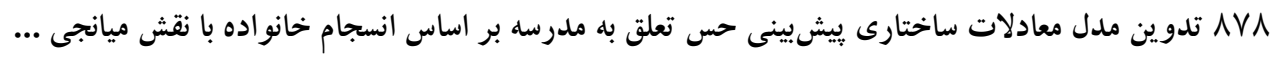

\title{
Developing a Structural Equation Model for Predicting the Sense of Belonging to School Based on Family Cohesion with the Mediating Role of Spiritual Intelligence in Secondary School Male Students in Ardabil in the Academic Year 2020-2021: A Descriptive Study
}

\author{
H. Taqavi', M. Javidpour ${ }^{r}$, Sh. Ahmadi ${ }^{r}$
}

Received: 25/05/21 Sent for Revision: 15/06/21 Received Revised Manuscript: 09/08/21 Accepted: 10/08/21

Background and Objectives: A sense of belonging to school has been recognized as an important requirement for students to perform well in learning environments. The aim of this study was to develop a structural equation model for predicting a sense of belonging to school based on family cohesion with the mediating role of spiritual intelligence in secondary high school male students.

Materials and Methods: This was a descriptive study using structural equation modelling and the statistical population of the present study consisted of all male high school students studying in public schools of Ardabil city in the academic year 2020-2021. A total of 250 of these individuals were selected by available sampling method and answered online questionnaires of sense of belonging to school, spiritual intelligence, and family cohesion. Data were analyzed using Pearson's correlation coefficient and structural equations modelling.

Results: The results showed that the sense of belonging to school was positively related to family cohesion ( $\mathrm{r}=0.35$, $\mathrm{p}<0.001)$ and spiritual intelligence $(\mathrm{r}=0.55, \mathrm{p}<0.001)$. Also, spiritual intelligence had a positive relationship with family cohesion $(r=37, p<0.001)$. Model fit indices also confirmed the path of family cohesion to the sense of belonging to school mediated by spiritual intelligence.

Conclusion: In general, the results showed that family cohesion directly and indirectly and mediated by spiritual intelligence, plays a role in the sense of belonging to school. In line with the results, holding educational workshops based on psychology to improve family relationships and teaching spiritual intelligence skills to parents and students will be a useful solution to increase family cohesion and thus a sense of belonging to school.

Key words: Sense of belonging to school, Spiritual intelligence, Family cohesion, Students, Ardabil

Funding: This study was funded by University of Mohaghegh Ardabili.

Conflict of interest: None declared.

Ethical approval: The Ethics Committee of Ardabili University of Medical Sciences approved the study (IR.ARUMS.REC.1400.056).

How to cite this article: Taqavi H, Javidpour M, Ahmadi Sh. Developing a Structural Equation Model for Predicting the Sense of Belonging to School Based on Family Cohesion with the Mediating Role of Spiritual Intelligence in Secondary School Male Students in Ardabil in the Academic Year 2020-2021: A Descriptive Study. J Rafsanjan Univ Med Sci 2021; 20 (8): 865-78. [Farsi]

1- Assistant Prof., Dept. of Educational Sciences, Faculty of Educational Sciences and Psychology, Mohaghegh Ardabili University, Ardabil, Iran, ORCID: 0000-0002-9489-4396

(Corresponding Author) Tel: (045) 31505642, Fax: (045) 31505642,E-mail: Taqavi@uma.ac.ir

2- PhD Student in Educational Administration, Faculty of Educational Sciences and Psychology, University of MohagheghArdabili, Ardabil, Iran, ORCID: 0000-0002-9955-8105

3- PhD Student in Psychology, Dept. of Psychology, School of Educational Sciences and Psychology, University of Mohaghegh Ardabili, Ardabil, Iran, ORCID: 0000-0003-0189-9575

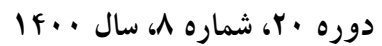

مجله دانشگاه علوم يزشكى رفسنجان 